\title{
Should we Hold the Obese Responsible?
}

\section{Some Key Issues}

Nielsen, Morten Ebbe Juul; Andersen, Martin Marchman

Published in:

Cambridge Quarterly of Healthcare Ethics

DOI:

$10.1017 / \mathrm{S} 0963180114000115$

Publication date:

2014

Document version

Early version, also known as pre-print

Citation for published version (APA):

Nielsen, M. E. J., \& Andersen, M. M. (2014). Should we Hold the Obese Responsible? Some Key Issues.

Cambridge Quarterly of Healthcare Ethics, 23(4), 443-451. https://doi.org/10.1017/S0963180114000115 


\title{
Special Section: Open Forum
}

2

\section{Should We Hold the Obese Responsible?}

\author{
Some Key Issues \\ MORTEN EBBE JUUL NIELSEN and MARTIN MARCHMAN ANDERSEN
}

Abstract: It is a common belief that obesity is wholly or partially a question of personal choice and personal responsibility. It is also widely assumed that when individuals are responsible for some unfortunate state of affairs, society bears no burden to compensate them. This article focuses on two conceptualizations of responsibility: backward-looking and forward-looking conceptualizations. When ascertaining responsibility in a backwardlooking sense, one has to determine how that state of affairs came into being or where the agent stood in relation to it. In contrast, a forward-looking conceptualization of responsibility puts aside questions of the past and holds a person responsible by reference to some desirable future state of affairs and will typically mean that that he or she is subjected to criticism, censure, or other negative appraisals or that he or she is held cost-responsible in some form, for example, in terms of demanded compensation, loss of privileges, or similar. One example of this view is the debate as to whether the obese should be denied, wholly or partially, free and equal access to healthcare, not because they are somehow personally responsible in the backward-looking sense but simply because holding the obese responsible will have positive consequences. Taking these two conceptions of responsibility into account, the authors turn their analysis toward examining the relevant moral considerations to be taken into account when public policies regarding obesity rely on such a conception of responsibility.

Keywords: obesity; personal responsibility; health care allocation; social inequality in health; distributive justice; luck egalitarianism

Many believe that most individuals are wholly or partially personally responsible for being overweight or obese: ${ }^{1}$ obesity is wholly or partially a question of choice. Many also believe that when an individual is responsible for some unfortunate state of affairs, then society does not owe that individual compensation. This view is central to the theory of luck egalitarianism, ${ }^{2}$ and many laypersons seem to agree. $^{3}$

Responsibility can be understood in many quite different senses. We shall focus on two central types of conception. A backward-looking conception of responsibility concerns, ultimately, control over (or some other form of relation to) choices and causes of some state of affairs, for which one can then be said to be responsible, or some other connection between prior and later states of affairs. When ascertaining whether or not an individual is responsible for some state of affairs, one has to look backward to how that state of affairs came to be or which relation the agent stood in vis-à-vis that state of affairs. The other rendering of responsibility is forward looking. This is the form of responsibility involved in, for example, deterrence. One might ignore questions of the past completely when arguing that

We would very much like to thank Nils Holtug of the Philosophy Department of the University of Copenhagen for helpful comments to this article. 
1 a person should be incarcerated-what justifies holding someone responsible is the expected outcome that it will deter other potential criminals, and so on.

Imagine that personal responsibility in the backward-looking sense is impossible, or at least so extremely unlikely to hold true that it is not intellectually honest to defend. Where would that leave "responsibility" in the moral landscape for decisionmakers, politicians, practitioners, and so on? Would the obese have no responsibility for the (eventual) ensuing consequences of their obesity? Dismissing the backward-looking notion of responsibility clearly implies that we should not-indeed, cannot-justify differential treatment (in a broad sense) of different citizens in virtue of their different levels of responsibility for prior choices or previous states of affairs. However, forward-looking responsibility-holding persons responsible, as it were-might still be justified, for example, on the grounds of efficiency or, ultimately, promotion of welfare. What are the relevant moral considerations to be taken into account when public policies regarding obesity rely on such a conception of responsibility? This is the question we want to pursue in this article.

In order to justify posing the question in this way, however, we need first to make a case for denying the cogency of backward-looking responsibility. This necessarily takes us into thorny patches of metaphysical discussion, such as the debate over free will, compatibilism, and agent causality. While running the risk of oversimplification, we attempt to make that journey as comfortable as possible.

We then turn to the practical implications of setting backward-looking responsibility aside for the question of obesity. We here focus on the following questions: Is it really efficient, in terms of welfare, to hold the obese responsible? If there are ways in which it is efficient, so understood, which other moral concerns are relevant? How would such a policy fit with due considerations about equal respect for differing conceptions of the good in liberal societies?

\section{The Impossibility of Backward-Looking Responsibility}

In this section we discuss the backward-looking idea of responsibility. First, we focus on a naturalistic approach to responsibility. By this we mean, roughly, an account that fits with the theories commonly held in the natural sciences. The argument here is that such a naturalistic view renders (backward-looking) responsibility impossible. We then briefly turn to two so-called compatibilistic accounts of responsibility. We argue that they are not ultimately convincing.

\section{The Naturalistic Approach to Responsibility}

In our daily practices it seems natural that we hold one another responsible for our actions, including at least some of our lifestyle characteristics. Suppose Sam complains about being obese at some get-together over coffee and then reaches out for a third piece of cake. Ignoring reasons of politeness, nothing seems more obvious than to ask, "Why don't you just leave it?" However, if we allow ourselves to ask why Sam eats this third piece of cake, it is not very obvious that Sam in fact can act differently. Consider Galen Strawson's "basic argument":

(1) It is undeniable that one is the way one is, initially, as a result of heredity and early experience, and it is undeniable that these are things for which one cannot be held to be in any way responsible (morally or otherwise). 
Should We Hold the Obese Responsible?

(2) One cannot in any later stage of life hope to accede to true moral responsibility for the way one is by trying to change the way one already is as a result of heredity and previous experience.

(3) For both the particular way in which one is moved to try to change oneself, and the degree of one's success in one's attempt at change, will be determined by how one already is as a result of heredity and previous experience.

(4) And any further changes that one can bring about only after one has brought about certain initial changes will in turn be determined, via the initial changes, by heredity and previous experience. ${ }^{4}$

Now, if we ask why Sam eats the third piece of cake, it seems that whatever cause we will find to explain it will itself be an effect of another cause, which also will be an effect of a cause, and so forth. We will soon realize that when Sam is eating the third piece of cake, it is the result of a chain of causes and effects involving not just Sam's earlier experiences but also in fact events and states before Sam was born, such as genes and epigenetic influences. Sam eats the third piece of cake simply due to reasons that are ultimately beyond Sam's control, and, similarly, if Sam changes eating behavior and somehow manage to eat less cake, it would also be due to reasons that are ultimately beyond Sam's control. How could Sam ever be responsible for that?

The naturalistic approach to responsibility can be expressed in two formal requirements: A person $\mathrm{P}$ is responsible for an act (or omission) $\mathrm{X}$ only if

1) P had the ability to do otherwise, that is, not to perform $X$ (the ability-to-dootherwise requirement). ${ }^{5}$

If every event in the world is determined by prior causes, then Sam can never do otherwise. However, we do not know if every event in the world is determined by prior causes. There may simply be random factors. If this is so, then Sam may have had the ability to do otherwise. But we are not looking for the ability to do otherwise due to random factors-we want Sam, not some random factors, to be the very cause of the action. We are looking for Sam's self-determination, and we therefore need a second requirement:

2) $\mathrm{P}$ is responsible for the causes of $\mathrm{X}$ (regression requirement). ${ }^{6}$

Combining the ability-to-do-otherwise requirement with the regression requirement, we cannot ascribe responsibility to Sam in cases in which Sam could have done otherwise, but only due to random factors. If Sam's choices and actions are determined or random, then Sam cannot be responsible. This seems indeed intuitively plausible, and if this is so, then responsibility begins to look impossible. However, there is one alternative remaining that may make responsibility possible given our two requirements. This is the possibility of agent causality.

Agent causality is the view that agents are able to start new causal chains that are neither predetermined nor completely random. However, agent causality is highly contestable, and no one seems to have given any fully satisfactory explanation of how it is supposed to work. ${ }^{7}$ It is of course difficult, if not impossible, to demonstrate the falsity of agent causality, but following a method of inference to the best 


\section{Morten Ebbe Juul Nielsen and Martin Marchman Andersen}

explanation, agent causality is probably ruled out. If Sam eats five cakes as an agent-causal performance, it follows that there is no further causal explanation as to why Sam did so other than Sam doing so: Sam did it, and that is the cause. But this seems to be a complete denial of the very strong and widespread intuition that events, including human acts, happen for causal reasons. If Sam eats five cakes, it seems to be a rather unsatisfying explanation just to say that Sam ate the cakes because Sam did so. Few would probably agree that Sam's decision to eat five cakes has no further causal explanations, such as psychological conditions and social circumstances. Thus, agent causality is probably false, and if so, then, on a naturalistic account, responsibility is impossible.

\section{Compatibilist Accounts of Responsibility}

The fact that Sam is eating the cakes is probably determined by heredity and earlier experiences. Unless agent causality is possible, Sam is therefore never able to do otherwise in such a way that satisfies the regression requirement. But one may challenge the very claim that the ability to do otherwise is what responsibility requires. One influential compatibilistic account focuses on our "true identity": if there is a correspondence between our first-order preferences and who we really want to be (our second-order volitions), then we are responsible. So, if Sam in fact wants to overeat, then Sam is responsible. ${ }^{8}$ Another compatibilistic approach to responsibility focuses on whether an agent is appropriately responsive to reasons. In Fischer and Ravizzas's influential account, it takes two things for an agent to be responsible. An agent must know the particular facts surrounding his action and must act with the right forms of beliefs and intentions in order to be responsible. ${ }^{9}$ Moreover, an agent must act from a mechanism that is the agent's own reasons-responsive mechanism. ${ }^{10}$ An agent is reason responsive if the mechanism on which he or she acts would, in some possible world in which there is reason to do otherwise, lead him or her to act on that reason and hence do otherwise. ${ }^{11}$ So, if Sam, in another possible world, would be responsive to relevant reasons not to overeat, then Sam is responsible.

These compatibilist accounts can be said to be ahistoric views of personal responsibility. Roughly, for the former account, what matters is the match or mismatch between an agent's deeply held preferences (identity) and first-order desires, and not the way in which this identity and these desires arose in the first place. For the latter, what matters is whether or not an agent would have responded differently to a counterfactual set of relevant reasons, and the history of the reasons-responsive mechanism is only captured by the requirement of the reasons-responsive mechanism to be the agents' own. This ahistoric tactic is probably necessary to avoid being entangled in a regress that will inevitably point back to some set of causal factors for which no individual can be responsible.

However, this tactic is also a weak spot in both theories, for it seems weird to ignore the past in an assessment of whether or not a given individual is responsible for his or her preferences, identity, or reason responsiveness. When we deliberate about whether or not Sam is responsible for his or her obesity or for its eventual medical consequences, we will, on these accounts, be lead to assess whether Sam identified (repeatedly) with eating the cakes (Was it a part of Sam's true identity?) or whether Sam was appropriately sensitive to reasons, and so on. But if it is a legitimate part of our assessment of Sam's (eventual) responsibility to look at such prior states of affairs, it seems legitimate as well to look at the conditions under 
1 which Sam's identity was formed, or the circumstances relevant for Sam's being

2 appropriately sensitive to reasons. Because one could hardly, if ever, be said to be

3 responsible for those conditions and circumstances, it seems wrong to claim that - Sam is responsible, all things considered. ${ }^{12}$

Moreover, most people are inclined to accept at least some set of excusing or mitigating circumstances when it comes to responsibility. For instance, many would probably accept that if a person is genetically predisposed to become obese 8 (e.g., the thrifty-gene hypothesis), then that would lessen responsibility. The same goes, mutatis mutandis, for social conditioning, epigenetic influences, and so on. ${ }^{13}$

10 However, the compatibilist theories just mentioned cannot cater to such intuitions: 11 what matters for them is only identity or reason responsiveness. If one does want 12 to stick to the intuition that genes (and so on) can affect and lessen responsibility, 13 then it seems that one has to go to the naturalistic account-which, inevitably, 14 leads to the conclusion that responsibility is impossible.

\section{The Forward-Looking Conceptualization of Responsibility: Implications and Moral Considerations}

Everything in the previous discussion concerns the backward-looking conceptualization of responsibility. We now turn to the forward-looking view. Such a rendering is defended by, among others, J. J. C. Smart. ${ }^{14}$ In a nutshell, a forward-looking conceptualization of responsibility justifies holding persons responsible by reference to some desirable future state of affairs: "Whatever responsibility is, considered as a metaphysical state, unless we can tie it to some recognizable social desideratum, it will have no rational claim on our esteem. ${ }^{\prime 15}$ Holding persons responsible will typically mean either that they are subjected to criticism, censure, or other negative appraisals or that they are held cost-responsible in some form, for example, in terms of demanded compensation, loss of privileges, or similar. A key example here is whether the obese should be denied, wholly or partially, free and equal access to healthcare, not because they are somehow personally responsible in the backwardlooking sense but simply because holding the obese responsible will have positive consequences (fewer obese people, lower healthcare costs, and so on). The following question then arises: should we hold the obese responsible (in the forward-looking sense) because it would have some desirable consequences?

Before addressing this question, let us make note of the relation between the two forms of responsibility. Analytically, these are distinct, but in one sense they overlap, because judgments about the justifiability of holding persons responsible for forward-looking reasons often rely on more or less implicit judgments concerning prior actions, and hence on backward-looking responsibility. What else could explain why most people think that deterrence can justify imprisoning criminals, but only very few think it justifiable to imprison an innocent, even if the effect of deterrence is the same? It is hard not to infer that notions of backwardlooking responsibility psychologically sweeten the pill for judgments concerning forward-looking responsibility, and this is probably exacerbated when the ones to be held responsible are socially or otherwise marginalized or stigmatized-the obese, smokers, alcoholics, and so on. But because, as we have argued, backwardlooking responsibility is a spurious concept, we claim that we are never justified in letting backward-looking responsibility influence judgments about the moral status or acceptability of forward-looking responsibility. 


\section{Morten Ebbe Juul Nielsen and Martin Marchman Andersen}

A very influential theory of justice in the contemporary political philosophical debate-luck egalitarianism-holds, roughly, that inequalities are unjust except when they "track choice" -implying that it is only if we are indeed responsible for an outcome that we can be held cost-responsible, ceteris paribus, ${ }^{16}$ and quite a few laypersons seem to agree. ${ }^{17}$ Following this theory, if the obese are not (backwardlooking) responsible, then eventual inequalities stemming from their obesity are indeed unjust-at least ceteris paribus. This latter clause is important, because, as we have mentioned, there might be other reasons that could justify holding the obese responsible in a forward-looking manner. ${ }^{18}$ Holding the obese costresponsible may be done, for example, by imposing consumer taxes on fatty food, or, taking a perhaps less sympathetic approach, by demanding that the obese pay for healthcare services related to obesity.

This raises a string of further questions. The first one we want to address is the following: is it efficient to hold individuals cost-responsible for the consequences of obesity? We are philosophers, and as such we are ill equipped to answer such empirical questions. However, we can qualify the question. The question ought, first of all, to be the following: does holding individuals responsible for the consequences of their obesity promote or protect welfare? Obesity is not intrinsically bad, nor is being lean necessarily good. Moreover, health is not a moral currency, and therefore policies should never be assessed in terms of their impact on health alone. Keeping this in mind, the design of policies and interventions relying on forward-looking responsibility are likely to be much more sensitive (and reasonably so) to all the welfare-affecting issues such policies will inevitably have: criticism and blame will likely lower the mental well-being of the obese, lead to increased stigmatization and stress, lower the status of the obese, and so forth. Imposing ex ante costs in the forms of, for example, fat taxes will lower the welfare of those who cannot or will not change their patterns of consumption. And of course, imposing costs on the obese for obesity-related diseases will likely dramatically lower opportunities and welfare for many obese. These and other relevant moral considerations are less likely to be obscured if one focuses on the real issue-welfare-rather than health, BMI, or similar. Moreover, it should always be the case that a given intervention is the most efficient way of raising or protecting welfare as compared with other courses of action. In sum, there are reasons to be skeptical about whether holding the obese responsible will in fact (best) promote welfare, all things considered.

An alternative way of arguing for the responsibilization of the obese takes its cue not from the purported goal of protecting the health and well-being of the obese but rather from protecting the interests of the healthy: it can be argued that the obese (statistically) impose (unfair) burdens on the healthy. ${ }^{19}$ It might then be argued that holding the obese responsible (given that it is effective) is justified at least partly because it serves the interests of the non-obese. Again, assessing whether and when this is the case is an empirical question and depends on how the relevant institutions are set up. However, some research points in the direction that, at least in more egalitarian societies with free and equal access to healthcare as the ideal, the obese are not in fact an all-things-considered economic burden, ${ }^{20}$ even before increased costs to public pensions (on the premise that preventing obesity will lead to increased longevity) are taken into consideration.

However, suppose that some way of holding the obese responsible is in fact best in terms of an all-things-considered aggregation of welfare. Utilitarians need not 


\section{Should We Hold the Obese Responsible?}

take other factors into consideration, but for those with other moral inclinations, it is necessary to pose the question, "At what price to other values, such as personal autonomy, equal respect, and so on, can society pursue policies that hold the obese cost-responsible?"21 Fleck here mentions three overall issues: trust in the doctor patient-relationship, privacy rights, and personal autonomy. The first two issues concern the fact that if doctors must act as gatekeepers or judges vis-à-vis the health behavior of citizens, then the bonds of trust between doctors and patients are undermined, and the doctor betrays some fundamental, role-related duties (which will more than likely have bad social consequences, apart from breaching those duties), including the duty to respect the privacy rights of the patients.

The third issue - the more general question of personal autonomy-relates to the perhaps most acute and controversial question in public health ethics, namely, the controversy over the role and status of personal liberty in the liberal tradition weighed against collective, aggregate interests, for example, of a more communitarian bent. 22 "The establishment of public health ethics as a discipline in its own right seems innately related to questioning the suitability of a liberal framework."23 In essence, the question concerns whether or not, or to which degree, it is justifiable to infringe or violate individual rights of liberty in order to pursue collective goals such as promoting aggregate welfare. In terms more familiar to political philosophers, the question concerns the issue of due respect for individuals' conception of the good: some might set for their own lives the goal of living the longest and healthiest life possible, but such an ideal will remain controversial and cannot command the allegiance of all reasonable citizens. This is, of course, a huge and hugely complicated issue. What remains uncontroversial, at least relatively speaking, is the fact that liberal values speak against heavy-handed responsibilization of the obese and other potential victims of so-called lifestyle diseases. This is because pursuing public health by political means runs the risk of violating the liberal requirement of neutrality between competing yet reasonable conceptions of the good. ${ }^{24}$ Imposing personal costs on citizens having an "indulgent" or "risky" lifestyle is easily translated into forms of moralizing that are incompatible with liberal values. Naturally, there are health-related cases of imposing costs on citizens that only few liberals would deem morally problematic. Outlawing the use of highly dangerous chemicals in food production is justifiable, because no reasonable conception of the good is compromised by that. Conversely, criminalization of the selling of fatty foods will unduly restrict some reasonable citizens' pursuit of their conception of the good. This of course leaves plenty of room for controversy, including family disputes within the liberal camp over cases that fall between these extremes. Nevertheless, on any plausibly liberal account, the suggestion to penalize some citizens' conception of the good (or evaluation of the value of health and longevity, if you want), even if this produces some socially desirable results, must be scrutinized closely and weighed against the values of public reason given the fact of pluralism, and these values should not be taken lightly. Moreover, we claim that all people, not just liberals, have good reasons to adopt this attitude toward forward-looking responsibilization of the obese. Given pluralism, the liberal vision of the legitimate use of the coercive powers of the state is the most cogent and persuasive on the market, and it is especially relevant when it comes to deeply controversial questions concerning the value of health. ${ }^{25}$ It is sometimes taken for granted that health claims are somehow less controversial than other lifestyle-related ones. ${ }^{26}$ In Rawlsian terms, health could be viewed as 


\section{Morten Ebbe Juul Nielsen and Martin Marchman Andersen}

something akin to a primary good, that is, something that all would want more rather than less of, irrespectively of their more particular comprehensive conception of the good. But although it is probably true that all reasonable citizens would prefer good health over bad, it is not true that all emphasize it equally. In particular, which kind of burdens and restrictions and policies and mandates that are acceptable in the pursuit of health will remain deeply controversial among reasonable citizens. In that light, responsibilization of the obese is bound to remain an at least prima facie dubious practice as seen from the light of public reason. In Gaus's terms, holding the obese responsible will likely be an authoritarian (tyrannical) rather than an authoritative (justified in the light of public reason) political act.

Here, a liberal rejoinder is possible. Most liberals, including liberal egalitarians, deny that a liberal political order is meant to produce equally good outcomes for all people, irrespective of their conception of the good. The individual with cheap tastes-say, jogging and spring water-will ceteris paribus face an easier challenge when it comes to preference satisfaction than the one with expensive tastes-say, for burgundy wine and opulent meals. Because this does not jeopardize neutrality on the standard Rawlsian interpretation of liberal egalitarianism, why should it jeopardize neutrality if we (within reason) make it harder for citizens with a taste for fatty foods to get their preferences satisfied, for example, by ex ante taxation of high-fat or high-calorie foods? Our answer is this: if the background for such a policy of ex ante taxation were that (1) the obese are an all-things-considered burden on other taxpayers, (2) the obese and the non-obese (actually or counterfactually) have equal starting points (i.e., there is no socioeconomic difference between the groups in favor of the non-obese), and (3) the policy is, or is reasonably expected to be, effective in terms of reducing bad consequences of obesity and/or promoting welfare, then holding the obese responsible on a forward-looking conception of responsibility is not necessarily in conflict with neutrality or liberal egalitarian values more generally. However, we find it unlikely that all of the three conditions hold true, or approximately true, in any society-or that they will ever hold true in any future one. Hence, we probably should not hold the obese responsible, on either a backward- or a forward-looking conception of responsibility.

\section{Notes}

1. See O'Brien KS, Latner JD, Halberstadt J, Hunter JA, Anderson J, Caputi P. Do antifat attitudes predict antifat behaviors? Obesity (Silver Spring) 2008;16 Suppl 2:87-92; Allison DB, Basile VC, Yuker HE. The measurement of attitudes toward and beliefs about obese persons. International Journal of Eating Disorders 1991;10:599-607; Crandall CS. Prejudice against fat people: Ideology and self-interest. Journal of Personality and Social Psychology 1994;66:882-94. Lund TB, Sandøe P, Lassen J. Attitudes to publicly funded obesity treatment and prevention. Obesity 2011;19(8):1580-5. Ten Have M, de Beaufort ID, Teixeira PJ, Mackenbach JP, van der Heide A. Ethics and prevention of overweight and obesity: An inventory. Obesity Reviews 2011;12(9).

2. See Segall S. Health, Luck and Justice. Princeton, NJ: Princeton University Press; 2010; Knight C. Luck Egalitarianism: Equality, Responsibility, and Justice. Edinburgh: Edinburgh University Press; 2009.

3. See note 1, Lund et al. 2011.

4. Strawson G. The impossibility of moral responsibility. In: Pojman LP, McLeod O, eds. What Do We Deserve? A Reader on Justice and Desert. Oxford: Oxford University Press; 1999, 114-24, at 115-16.

5. Hurley S. Justice, Luck, and Knowledge. Cambridge, MA: Harvard University Press; 2003.

6. See note 5, Hurley 2003.

7. For a contemporary philosopher who defends agent causality, see Kane R. Free will: New directions for an ancient problem. In: Fischer JM, ed. Free Will: Critical Concepts in Philosophy, Vol. III: Libertarianism, Alternative Possibilities, and Moral Responsibility. New York: Routledge; 2005. 


\section{Should We Hold the Obese Responsible?}

8. Frankfurt HG. Alternate possibilities and moral responsibility. Journal of Philosophy 1969;66: 829-39.

9. Fischer JM, Ravizza M. Responsibility and Control: A Theory of Moral Responsibility. Cambridge: Cambridge University Press; 1998.

10. See note 9, Fischer, Ravizza 1998.

11. See note 5, Hurley 2003.

12. Matravers M. Responsibility and Justice. Malden, MA: Polity Press; 2007.

13. Sharkey K, Gillam L. Should patients with self-inflicted illness receive lower priority in access to healthcare resources? Mapping out the debate. Journal of Medical Ethics 2010;36:661-5; Brownell KD, Kersh R, Ludwig DS, Post RC, Puhl RM, Schwartz MB, Willett WC. Personal responsibility and obesity: A constructive approach to a controversial issue. Health Affairs 2010;3:378-86.

14. Smart JJC. Free-will, praise, and blame. Mind 1961;70:291-306; see also Arneson RJ. The Smart theory of moral responsibility and desert. In: Olsaretti S, ed. Desert and Justice. Oxford: Oxford University Press; 2003.

15. Dennett DC. Elbow Room: The Varieties of Free Will Worth Wanting. Cambridge, MA: MIT Press; 1984 , at 163 .

16. See note 2, Segall 2010 and Knight 2009.

17. See note 1, Lund et al. 2011.

18. Buyx AM. Personal responsibility for health as a rationing criterion: Why we don't like it and why maybe we should. Journal of Medical Ethics 2008;34(12):871-4.

19. Fleck L. Whoopie pies, super-sized fries: "Just" snacks? "Just" des(s)erts? Cambridge Quarterly of Healthcare Ethics 2012;21(1):5-19.

20. Van Baal PHM, Polder JJ, Ardine de Wit G, Hoogenveen RT, Feenstra TL, Boshuizen HC, et al. Lifetime medical costs of obesity: Prevention no cure for increasing health expenditure. PLoS Medicine 2008;5(2):e29. doi:10.1371/journal.pmed.0050029.

21. See note 19, Fleck 2012.

22. See, e.g., Dawson A. The future of bioethics: Three dogmas and a cup of hemlock. Bioethics 2010; 24:218-25. doi:10.1111/j.1467-8519.2010.01814.x.

23. Radoilska L. Public health ethics and liberalism. Public Health Ethics 2009 July;2(2):135-45, at 135. doi:10.1093/phe/php010.

24. Rawls J. Political Liberalism. New York: Colombia University Press; 1993.

25. The most recent comprehensive formulation of a public-reason-based form of liberalism comes from Gaus G. The Order of Public Reason: A Theory of Freedom and Morality in a Diverse and Bounded World. Cambridge: Cambridge University Press; 2011.

26. See, from a critical perspective, Sher G. Beyond Neutrality. Cambridge: Cambridge University Press; 1997, at 38 . 


\section{AUTHOR QUERIES}

QA $\quad$ The distinction between surnames can be ambiguous, therefore to ensure accurate tagging for indexing purposes online (eg for PubMed entries), please check that the highlighted surnames have been correctly identified, that all names are in the correct order and spelt correctly. 